\title{
Emerging Systemic Therapeutic Approaches for Personalized Medicine in Squamous Cell Carcinoma of the Lung
}

\section{Grace Kho Dy*}

Department of Medicine, Roswell Park Cancer Institute, USA

\begin{abstract}
During the past decade, a number of novel agents developed for the treatment of advanced NSCLC had, by coincidence, shown survival benefit predominantly among patients with nonsquamous histology, namely pemetrexed (anti-folate), bevacizumab (VEGF pathway inhibition), erlotinib/gefitinib (EGFR receptor tyrosine kinase inhibitors) and crizotinib (ALK receptor tyrosine kinase inhibitor. This has sparked a heightened interest in discovering key molecular aberrations that may be relevant for the treatment of squamous cell carcinoma (SCC) of the lung, a histologic subtype that represents approximately $25 \%$ of lung cancer cases diagnosed globally. This article highlights the most promising recent discoveries and targeted agents in development that may be relevant for the treatment of SCC of the lung.
\end{abstract}

\section{Introduction}

During the past decade, a number of novel agents developed for the treatment of advanced NSCLC had, by coincidence, shown survival benefit predominantly among patients with nonsquamous histology, namely pemetrexed (anti-folate), bevacizumab (VEGF pathway inhibition), erlotinib/gefitinib (EGFR receptor tyrosine kinase inhibitors) and crizotinib (ALK receptor tyrosine kinase inhibitor) [15]. This has sparked a heightened interest in discovering key molecular aberrations that maybe relevant for the treatment of squamous cell carcinoma (SCC) of the lung, a histologic subtype that represents approximately $25 \%$ of lung cancer cases diagnosed globally [6]. This article highlights recent discoveries and targeted agents in development that may be relevant for the treatment of SCC of the lung.

\section{Fibroblast Growth Factor Receptor (FGFR)}

The fibroblast growth factor family of 22 ligands variably interacts with 4 highly conserved transmembrane FGFR tyrosine kinases. Dysregulated signaling have been identified in various malignancies, via amplification, point mutation or translocations, which contribute to carcinogenesis such as increased proliferation, anti-apoptosis, cell migration and angiogenesis [7]. Examples include activating FGFR2 point mutations in endometrial carcinomas [8], FGFR2 amplification and point mutations in gastric carcinomas $[9,10]$, FGFR3 activating point mutations in bladder carcinomas [11], FGFR3 overexpression arising from $\mathrm{t}(4 ; 14)(\mathrm{p} 16: \mathrm{q} 32)$ translocation in multiple myeloma [12], FGFR4 amplification and point mutations in rhabdomyosarcomas [13], as well as amplification of FGFR1, FGFR2 and FGFR4 in breast cancer $[14,15]$. More recently, genomic analyses have shown frequent high level of FGFR1 amplification in a region of chromosome segment 8p12 by FISH in approximately $20 \%$ of SCC of the lung found in smokers [16]. More significantly is that this amplification underlies sensitivity to treatment with small molecule FGFR kinase inhibitors [16,17]. Few cases of FGFR2 point mutations in SCC of the lung have also been reported $[18,19]$. Nonetheless, wild type FGFR2 is functionally relevant as it cooperates with SOX2, which is commonly amplified in SCC of the lung, to achieve the latter's oncogenic potential [20]. Moreover, FGFs are frequently coexpressed with FGFR1 or FGFR2 in NSCLC, suggesting presence of autocrine signaling which can be inhibited by FGFR small molecule TKI. In contrast, cell lines lacking FGF/FGFR co-expression are not affected [21]. Specific selectivity for FGFR alone maybe a disadvantage compared to ability to cross-inhibit the related PDGFR- $\alpha$ kinase, as the latter maybe relevant in certain model systems exhibiting FGFR overexpression arising from non-focal chromosome 8 p12 amplification [16]. More-over, co-occurrence of other activated signaling pathways, such as constitutively activated MAPK pathway may underlie intrinsic resistance to FGFR1 inhibition [17]. Due to the high degree of homology between VEGFR2, PDGFR and FGFR kinase domain, a number of oral multikinase inhibitors in clinical use in fact demonstrates inhibition of FGFR in nanomolar concentrations as well albeit across a wide range (Table 1). A number of small molecule inhibitors have subsequently been developed to have more potent selectivity for FGFR kinase, such as dovitinib and brivanib. Indeed, there is suggestion that objective tumor response is better in FGF2positive relative to FGF2-negative tumors in the dose-escalation phase I trial of brivanib [22]. Nonetheless, VEGF pathway inhibition remains clinically relevant with these agents, as hypertension is often seen as an adverse effect in early clinical trials [23-25]. Otherwise, nausea, vomiting, diarrhea are commonly encountered across all agents. In contrast to other multikinase inhibitors, incidence of all-grade handfoot skin reaction (HFSR) is $<5 \%$ for pazopanib, nintedanib and the more selective FGFR inhibitors such as dovitinib, brivanib. A somewhat unique pharmacokinetic feature of dovitinib discovered based on dosing schedules utilized in the early phase I studies was an over proportional increase in dose and exposure relationship beyond $400 \mathrm{mg} /$ day of continuous daily dosing. Population pharmacokinetic/ pharmacodynamic modeling suggested that intermittent dosing could prevent prolonged drug accumulation and lead to better tolerance and thus currently the 5-days on/2-days off dosing schedule for dovitinib at $500 \mathrm{mg} /$ day is employed in ongoing monotherapy studies [26].

*Corresponding author: Grace Kho Dy, MD, Department of Medicine, Roswell
Park Cancer Institute, Buffalo, NY, USA, E-mail: Grace.Dy@RoswellPark.org Received March 01, 2012; Accepted March 21, 2012; Published March 23, 2012

Citation: Dy GK (2012) Emerging Systemic Therapeutic Approaches for Personalized Medicine in Squamous Cell Carcinoma of the Lung. J Cancer Sci Ther S11:003. doi:10.4172/1948-5956.S11-003

Copyright: @ 2012 Dy GK. This is an open-access article distributed under the terms of the Creative Commons Attribution License, which permits unrestricted use, distribution, and reproduction in any medium, provided the original author and source are credited. 
Newer orally administered small molecule inhibitors currently in development with even better selectivity for FGFR include LY2874455, BGJ398, and AZD4547. BGJ398's selectivity for FGFR 1-3 was demonstrated in vivo by dose-dependent inhibition of bFGFstimulated angiogenesis but no corresponding impairment of VEGFinduced angiogenesis [27]. Phase I study of this agent is ongoing, with the study design reflecting the recognition that rationale-based, biomarker-driven patient enrichment design is ethical and feasible even in early clinical development of targeted agents. This phase I study, which started in $12 / 2009$, is limited to patients with tumor that have FGFR1 or FGFR2 amplification or FGFR3 mutations. It started enrolling FGFR1-amplified NSCLC patients in the first quarter of 2011. Similarly, the phase I study of AZD4547, started in 9/2009, is recruiting only patients with tumors that have FGFR1 or FGFR2 amplification or overexpression. LY2874455, which is a dominant pan-FGFR inhibitor, exhibits approximately 6-9 fold selectivity on inhibition of FGF-over VEGF-mediated signaling in vivo. No appreciable blood pressure changes were seen in murine models at doses that achieve inhibition of xenograft growth, which can inhibit FGFR by $90 \%$ but VEGFR2 at $<50 \%$ [28]. A phase I study which started recruiting patients in $12 / 2010$ with advanced malignancies is ongoing. Ponatinib is a multikinase inhibitor that was developed to inhibit both native (IC50 $0.37 \mathrm{nM}$ ) and mutant forms of bcr-abl, including T351I (IC50 $2 \mathrm{nM}$ ) in patients with chronic myelogenous leukemia [29]. Preclinical models demonstrate its ability to inhibit growth of FGFR1-amplified squamous cell lung cancer xenografts as well as greater potency in inhibiting all activated forms of FGFR1-4 compared to dovitinib, brivanib, cediranib and nintedanib [30]. Common toxicities, reported in the phase II PACE study in CML, showed rash, myalgia, abdominal pain, headache, arthralgia and thrombocytopenia which reflect class-effects of bcrabl inhibitors. Unusual severe adverse event include pancreatitis [31]. Thus, whether this agent can achieve meaningful antitumor efficacy for FGFR-driven solid malignancies along with acceptable safety profile in lung cancer patients, many of whom have comorbidities, is unknown. Other clinical trials of small molecule FGFR inhibitors specifically in SCC of the lung involve nindetanib- one is an ongoing phase I/II study which started in April 2011 combining nintedanib with cisplatin and gemcitabine as first-line therapy (NCT01346540). The second is a planned phase I study combining nintendanib and everolimus in all solid tumors with an expansion phase for patients with FGFR1amplified NSCLC (NCT013492960).

\section{PI3K (phosphoinositide 3-kinase) Pathway}

The PI3K signaling pathway has a prominent role in regulating cancer cell growth and survival [32]. Class I PI3Ks are comprised of 4 isoforms of the catalytic p110 subunit: $\alpha, \beta, \delta$ and $\gamma$, with the cell proliferation and growth principally the function of the p110a isoform. p110 (as well as the $\beta$ and $\gamma$ isoforms) are in turn regulated by p85-like regulatory subunits. Akt, the main effector, is activated downstream to PI3K, which in turn results in signaling chiefly through mTORC1. The mechanism of AKT activation by PI3K is regulated by the phosphatase and tensin homologue deleted on chromosome 10 (PTEN) tumor suppressor gene [33]. The PI3K pathway can be activated horizontally by inputs via receptor tyrosine kinase and $G$ protein-coupled receptor signaling (e.g. Ras family) or constitutively by genetic abnormalities. Somatic activating mutations in the PIK3CA gene, which encodes for the catalytic p110a subunit of PI3K, have been described in various malignancies such as colorectal, ovarian cancers, including lung cancers [34]. This has been reported to occur in approximately $2-4 \%$ of NSCLC and in approximately $1-10 \%$ of squamous cell lung carcinomas, with the most common mutations being in the helical domain encoded by exon 9 (E542 K, E545K) which interfere with p85 $\alpha$ binding and in the kinase domain encoded by exon 20 (H1047R, H1047L) [35-37]. Preclinical as well as early clinical studies have shown that presence of PIK3CA mutations in cancer cells confer treatment sensitivity to single-agent PI3K pathway inhibitors [34,38]. Presence of PIK3CA amplification, found in $43-65 \%$ of SCC of the lung, appears to be mutually exclusive with the presence of PIK3CA mutations [37,39]. The oncogenic effects of PIK3CA mutations however appear greater compared to PIK3CA amplification [37], suggesting that therapeutic effects of PI3K inhibitors will be greatest against tumors with mutant PIK3CA relative to PIK3CA-amplified tumors. Preclinical studies have

\begin{tabular}{|c|c|c|c|c|c|c|}
\hline \multirow{2}{*}{ Drug } & FGFR1 & FGFR2 & FGFR3 & FGFR4 & VEGFR2 & \multirow{2}{*}{ Reference } \\
\hline & \multicolumn{5}{|c|}{$\mathrm{IC}_{50}(\mathrm{nM})$} & \\
\hline Nintedanib & $\begin{array}{l}47 \\
69\end{array}$ & $\begin{array}{l}63 \\
37\end{array}$ & $\begin{array}{l}122 \\
108\end{array}$ & $\begin{array}{l}451 \\
610\end{array}$ & 21 & $\begin{array}{l}{[29]} \\
{[82]}\end{array}$ \\
\hline Brivanib & $\begin{array}{c}165 \\
15\end{array}$ & $\begin{array}{c}202 \\
32\end{array}$ & $\begin{array}{c}530 \\
52\end{array}$ & $\begin{array}{c}2023 \\
>1000\end{array}$ & 4.2 & $\begin{array}{l}{[29]} \\
{[83]}\end{array}$ \\
\hline Dovitinib & $\begin{array}{l}16 \\
13\end{array}$ & $\begin{array}{l}50 \\
21\end{array}$ & $\begin{array}{l}53 \\
18\end{array}$ & $\begin{array}{l}341 \\
470\end{array}$ & 5.4 & $\begin{array}{l}{[29]} \\
{[83]}\end{array}$ \\
\hline Cediranib & $\begin{array}{c}5 \\
26\end{array}$ & 33 & 36 & 697 & $<1$ & $\begin{array}{l}{[29]} \\
{[84]}\end{array}$ \\
\hline Ponatinib & 2 & 2 & 18 & 8 & 1.5 & [29] \\
\hline Sunitinib & 437 & 852 & 314 & & 34 & [81] \\
\hline Sorafenib & 64 & 825 & 1019 & & 28 & [81] \\
\hline Pazopanib & 80 & 350 & 138 & & 15 & [81] \\
\hline Axitinib & 231 & & & & 0.2 & [85] \\
\hline LY2874455 & 2.8 & 2.6 & 6.4 & 6 & 7 & [28] \\
\hline AZD4547 & 0.2 & 2.5 & 1.8 & 165 & & [86] \\
\hline BGJ398 & 0.9 & 1.4 & 1 & 60 & 180 & [27] \\
\hline Regorafenib & 202 & & & & $4.2 \dagger$ & [87] \\
\hline XL228 & 8 & 2 & 3 & & & [88] \\
\hline
\end{tabular}

*Data may vary between different references for the same compound due to differences in assay methodology. References that compare potency across various agents are preferentially cited when available. † murine VEGFR2

Table 1: Comparison of FGFR/VEGFR kinase inhibition profile of various FGFR inhibitors*. 
shown that resistance to PI3K inhibitors in PIK3CA-mutant tumors maybe mediated by presence of activated RAS/RAF/MEK pathway [40]. Of relevance is that while PIK3CA mutations frequently coexist with EGFR or K-ras mutations in lung adenocarcinomas [41], this is not the case with pure SCC of the lung [35]. Loss of PTEN is associated with PI3K pathway activation and this molecular event is found in 24$44 \%$ of NSCLC tumors as assessed by absent PTEN protein expression as determined by IHC, and up to $75 \%$ if cases with weak PTEN expression were included [42,43]. Published results show discordant data on the association of PTEN loss with tumor stage in SCC of the lung $[43,44]$. Nonetheless, genetic aberrations as a mechanism of PTEN loss, such as by mutation or homozygous deletion, are rare in lung cancer. Epigenetic silencing, such as promoter methylation, may partially explain some cases $[42,43]$. Recent data suggests that inactivation of p110 $\beta$ can counteract the effect of PTEN loss and that a pan-PI3K inhibitor will have greater antitumor efficacy compared to a isoform-specific PI3K inhibitor without activity against p110 $\beta$ although responses can still be seen $[45,46]$.

The Akt family of kinases is comprised of 3 isoforms, Akt1, Akt 2 and Akt3. There is relative specificity in each isoform's regulation of cellular processes, such as anti-apoptosis/cell survival for Akt1, maintenance of glucose homeostasis for Akt2 and brain development for Akt3. However, considerable overlap exists in their function such that functional isoform-specific signaling may be irrelevant with aberrant Akt activation [47]. The oncogenic E17K mutation in exon 4 of the plekstrin homology (PH) domain of Akt1 occurs in 6-8\% of colorectal and breast malignancies [48]. While rare in NSCLC, it appears to be primarily found in squamous cell lung carcinoma, reported in $1-1.5 \%$ of squamous cell lung cancers $[35,49,50]$. This mutation is associated with increased membrane localization which results in increased autophosphorylation of AKT1, increased levels of cyclin D1 and reduced the sensitivity to an allosteric Akt kinase inhibitor $[48,50]$. The occurrence of AKT1 mutation and PIK3CA mutations are generally mutually exclusive events $[48,51]$.

The first-generation PI3K inhibitors, such as wortmannin and LY294002 have been used extensively in preclinical models but are poorly soluble and toxic, likely due to off-target effects against unrelated enzymes such as polo-like kinases [52]. As both p110a and p110 $\beta$ mediate signals downstream of insulin receptor, hyperglycemia/ diabetes is a mechanism-based class effect of PI3K inhibitors. Other common side effects reported include rash, mucositis, fatigue and diarrhea. Various PI3K inhibitors have been developed and are in clinical development (Table 2). CAL-101 (also known as GS-1101) is a potent $\mathrm{p} 110 \delta$-selective inhibitor being developed for hematological malignancies, with promising role as well in chronic inflammatory diseases as well since p110 $\delta$ is mainly expressed in leukocytes [53]. Phase I study of GSK1059615 was terminated prematurely due to lack of sufficient exposure following single- and repeat-dosing [54]. GDC0941, an oral reversible pan-inhibitor of Class I PI3K, is currently being evaluated in a multi-arm randomized phase II study in combination with carboplatin and paclitaxel, with or without bevacizumab, as firstline treatment (NCT01493843) in molecularly unselected NSCLC based on promising phase Ib results of this combination, particularly in the squamous subset of patients [55]. A prerequisite is the availability of archival or fresh tissue which will be used to conduct biomarker assessments. BKM120, an oral reversible pan-PI3K inhibitor exhibited preferential inhibition of PIK3CA mutant tumors, in contrast to either Kras or PTEN mutant models in preclinical studies [56]. Mood alteration such as anxiety and depression were reported in up to $20 \%$, likely due to its ability to cross the blood-brain barrier [57]. There is an ongoing two-stage randomized phase II study of BKM120 as second line agent in comparison with docetaxel for SCC of the lung with evidence of activated PI3K pathway in archival/fresh biopsy specimen (NCT01297491). Currently being planned is a phase II study of BKM120 in various tumor types, including NSCLC, which have PIK3CA mutations E542K, E545K, H1047R, H1047L (NCT01501604). $\mathrm{XL147}$ is another oral reversible pan-PI3K inhibitor which is being evaluated in a phase I study in combination with carboplatin and paclitaxel as treatment for advanced solid tumors including NSCLC (NCT00756847). Phase I single-agent study showed a confirmed partial response in a patient with NSCLC with wildtype PIK3CA but PTEN status is unknown. Pharmacodynamic studies in post-treatment biopsies shows reduction in pERK, which is notable as phosphorylation of ERK1/2 and MEK1/2 are generally not inhibited by these agents $[58,59]$. PX-866 is an oral irreversible pan-inhibitor of Class I PI3K synthetically derived from wortmannin though with ten-fold greater potency and nearly 3 -fold less hepatotoxicity in murine toxicology studies relative to wortmannin [60]. A phase I single-agent study showed transaminase elevation as one of the dose-limiting toxicities [61]. It is currently being evaluated in randomized phase II study in combination with docetaxel versus docetaxel alone in patients with

\begin{tabular}{|c|c|c|c|c|c|c|}
\hline Drug & $\mathrm{p} 110 \alpha$ & $\mathrm{p} 110 \beta$ & $\mathrm{p} 110 \delta$ & $\mathrm{p} 110 \mathrm{y}$ & mTOR & Reference \\
\hline GDC-0941 & 3 & 33 & 3 & 75 & & {$[89,90]$} \\
\hline PX-866 & 6 & $>300$ uM & 3 & 9 & & [91] \\
\hline BKM120 & 52 & 166 & 116 & 262 & 2866 & [56] \\
\hline XL147 & 39 & 383 & 36 & 23 & $>15000$ & [92] \\
\hline ZSTK474 & 16 & 44 & 5 & 49 & & [93] \\
\hline CAL-101 & $>100$ uM & 1820 uM & 70 & 1240 & & [94] \\
\hline CH5132799 & 14 & 120 & 500 & 36 & 1600 & [62] \\
\hline PF-04691502 & 1.8 & 2.1 & 1.6 & 1.9 & 16 & {$[64]$} \\
\hline PF- 05212384 & 0.4 & 6 & 8 & 6 & 1 & [65] \\
\hline GSK2126458 & 0.019 & 0.13 & 0.024 & 0.06 & 0.18 & [95] \\
\hline XL765 & 39 & 113 & 43 & 8 & 157 & [96] \\
\hline BEZ235 & 4 & 75 & 7 & 5 & 21 & [97] \\
\hline SF1126 & 356 & 736 & 3225 & 1774 & 1060 & [98] \\
\hline GDC-0980 & 5 & 27 & 7 & 14 & 17 & [99] \\
\hline
\end{tabular}

Table 2: Comparison of kinase inhibition profile of various PI3K inhibitors ( $\mathrm{IC}_{50}$ in $\left.\mathrm{nM}\right)$. 
advanced NSCLC or squamous cell carcinoma of the head and neck (NCT01204099).

BYL719, GDC-0032, INK-1117 are isoform-specific p110aselective inhibitors developed to potentially increase magnitude of target $\mathrm{p} 110 \mathrm{a}$ inhibition by attenuating toxicities related to modulation of the other isoforms. CH5132799 has relatively greater selectivity for p110- $\alpha$, with approximately 2 -fold greater potency against common PIK3CA mutants relative to wildtype p110 $\alpha$ [62]. It demonstrated activity against some PTEN-deficient tumors, although likely the effect will have been more pronounced in the presence of $p 110 \beta$ inhibition as previously described [46]. These agents are undergoing dose-escalation monotherapy studies in unselected population with exception of an ongoing phase I study of BYL719 limited to patients with confirmed PIK3CA abnormality (mutation or amplification) (NCT01219699).

The dual ATP-competitive PI3K/mTOR kinase inhibitors have efficacy in inhibiting both mTORC1 and mTORC2 aside from the PI3K family. This is an important feature as an undesired consequence of isolated mTORC1 inhibition, such as with rapamycin analogs, is the activation of Akt due to abrogation of the negative feedback loop [63]. PF-04691502 (orally administration) and PF-05212384 (intravenously administered, also known as PKI-587) have shown effective preclinical activity against NSCLC xenograft models harboring dual PTEN deletion/EGFR mutation or dual PIK3CA mutation with either Kras or EGFR mutation $[64,65]$. Early phase I clinical data shows good tolerability but no objective tumor responses to date even in tumors with PIK3CA mutation [66,67]. Preclinical studies of BEZ235 show that its efficacy maybe predominantly related to its $\mathrm{mTOR}$ kinase inhibition, whereby at low drug concentrations $(<100 \mathrm{nM})$, mTOR inhibition predominates with corresponding induction of Akt phosphorylation, which is eliminated either by exposure at a higher concentration to achieve dual mTOR/PI3K blockade $(500 \mathrm{nM})$ or by the combination of an IGF-1R tyrosine kinase inhibitor [68]. Early clinical studies showed an objective tumor response in a NSCLC patient with Cowden syndrome [69]. As alluded to earlier, response to PI3K inhibitors maybe limited in PIK3CA mutants due to frequent coexistence of activated RAS/RAF/MEK pathway. Preclinical studies show that combination with a MEK inhibitor may overcome this resistance [40,56]. Moreover, the compensatory activation of ERK observed with the use of PI3K inhibitors as a mechanism of treatment resistance has been described [70]. Thus, phase I studies evaluating the combination of PI3K inhibitors with MEK inhibitors are ongoing or being planned (e.g. BKM120 with MEK162 or GKS1120212; BEZ235 with MEK162; BYL719 with MEK162; GDC0941 with GDC-0973, XL147 with MSC1936369B, PF-04691502/PF-05212384 with PD0325901; GSK2126458 with GSK1120212).

Various oral ATP-competitive pan-AKT inhibitors, such as GSK2110183, GSK2141795, GDC-0068, and AZD5363 are in early clinical development. These agents may have activity against cancers with the E17K AKT1 mutation, in contrast to potentially reduced efficacy of allosteric inhibitors against this AKT1 mutant [48]. While downstream signaling is inhibited, the ATP-competitive pan-AKT inhibitors, as a class-effect, induce hyperphosphorylation of AKT termed 'inhibitor hijacking of kinase activation", possibly through a conformational change [71]. MK2206 is an oral PH domain-dependent allosteric inhibitor with relatively greater potency against AKT1 and AKT2 (IC 50 of 5 and $12 \mathrm{nM}$, respectively) compared to AKT3 (IC50 of $65 \mathrm{nM}$ ) [72]. It induces a closed or inactive conformation of AKT, abrogates AKT phosphorylation and disrupts membrane localization [73]. Adverse effects observed in early clinical trials show spectrum of side effects consisting of skin rash, nausea, hyperglycemia and diarrhea similar to PI3K inhibitors [72]. A multiarm phase II study for NSCLC implemented in the first quarter of 2011 is ongoing, which prospectively assigns patients to specific kinase inhibitors according to the result of tumor molecular profiling (NCT01306045). Patients with PIK3CA, AKT or PTEN mutations will be allocated to the MK2206 treatment arm. In terms of predictive biomarkers, there appears to be a relationship between the presence of PIK3CA mutations or PTEN loss with sensitivity to AKT inhibitors, and the presence of activated Ras pathway with resistance which may be overcome by combination with MEK inhibitors in lung cancer models [74-76]. A phase I study evaluating the combination of MK2206 with the MEK inhibitor AZD6244 is ongoing, with expansion cohort limited to NSCLC with Kras mutations or other specific (undisclosed) mutations (NCT01021748)

\section{Discoidin Domain Receptor 2 (DDR2)}

DDR2 is a receptor tyrosine kinase that is activated by collagen binding and Src phosphorylation, thereby regulating various processes such as cell differentiation, extracellular matrix remodeling and cell migration [77,78]. Mutations in DDR2, both in the kinase domain and other regions, have been recently identified in approximately $3 \%$ of SCC of the lung based on a sequencing screen for recurrent mutations in this tumor type, with a total of 11 DDR2 mutations found in 290 samples (9 in 277 primary tumor specimen) [79]. There were no alterations in DDR2 gene copy number or protein overexpression found. This seminal finding generated significant attention as the investigators demonstrated that the mutations are oncogenic and that dasatinib, a dual src/abl kinase inhibitor, can block mutant DDR2, both kinase and non-kinase domain forms, in in vitro and in vivo preclinical models. Moreover dual inhibition of DDR2 and Src demonstrated additive efficacy against DDR2-transformed cell lines. The authors also reported that in a patient with EGFR-wildtype SCC of the lung harboring the DDR2 kinase domain mutation, treatment with a combination of erlotinib and dasatinib resulted in objective tumor response [79]. Of note, dasatinib, has the most potent activity against DDR2 (IC50=1.4 nM) compared to other kinase inhibitors such as imatinib (IC50 $=675 \mathrm{nM}$ ), nilotinib (IC50 $=55 \mathrm{nM}$ ), sorafenib (IC50=55 $\mathrm{nM}$ ) and pazopanib (IC50=474 $\mathrm{nM}$ ) $[80,81]$. Dasatinib is currently being evaluated in a phase II study as monotherapy for patients with SCC of the lung (NCT014916330).

\section{Conclusion}

A great progress has recently been made in identifying key oncogenic aberrations in SCC of the lung. The race is on for the first pharmacologic agent with good therapeutic index that will achieve meaningful clinical benefit for patients with this diagnosis. The modulation of FGFR1 appears to hold the most promise, due to its relative prevalence and panoply of drugs in development. However, success will depend on understanding additional pharmacokinetic and pharmacodynamic factors that influence antitumor efficacy of these drugs in development. Another practical issue that faces the clinical development of these targeted therapies is the validation, in tandem, of predictive markers for treatment sensitivity and resistance. Moreover, 
the assay for this biomarker should have sufficient sensitivity to detect low-frequency aberrations, either in fresh/frozen tumor or paraffinembedded specimen, particularly as tumor cells can be heterogeneous and background material of normal tissue cannot be avoided. Ideally, this should be incorporated into a platform capable of multiplex testing a large panel of candidate genes to fully utilize the typically small quantity of tumor genetic material available, such as the Sequenom Mass ARRAY system. However, this requires dedicated technological, human and financial resources that may not be readily available for the community practitioner. Because immunohistochemical and tissue microarray methods are readily available in pathology laboratories, developing this is another feasible approach though this maybe hampered by availability of relevant antibodies, optimization required and the relative tissue requirement compared to high-throughput methods even with TMAs. It is likely that with the rapid drop in cost of sequencing in line with technical advances, next-generation sequencing. As relevant is the need to understand both intrinsic and acquired resistance to therapy. This entails incorporating patient selection based on molecular profiling during the earlier phases of clinical testing as well as the need to perform multiple evaluations, such as biopsies, along each patient's treatment course that will enable elucidation of the genetic or signaling events that mediate acquired treatment resistance. More importantly, when multiple agents having similar spectrum of activity are being developed contemporaneously by different drug companies, there should be a collaborative effort in developing new study designs that will permit an efficient means of clinical testing, in a fashion akin to what has been spearheaded by the I-SPY2 investigators. This is a highly pertinent concern particularly when the patient population for clinical trials is limited by the low prevalence rate of an oncogenic drug target.

\section{References}

1. Scagliotti G, Brodowicz T, Shepherd FA, Zielinski C, Vansteenkiste J, et al. (2011) Treatment-by-histology interaction analyses in three phase III trials show superiority of pemetrexed in nonsquamous non-small cell lung cancer. J Thorac Oncol 6: 64-70.

2. Sandler A, Gray R, Perry MC, Brahmer J, Schiller JH, et al. (2006) Paclitaxelcarboplatin alone or with bevacizumab for non-small-cell lung cancer. N Engl J Med 355: 2542-2550.

3. Shepherd FA, Rodrigues Pereira J, Ciuleanu T, Tan EH, Hirsh V, et al. (2005) Erlotinib in previously treated non-small-cell lung cancer. N Engl J Med 353: 123-132.

4. Mok TS, Wu YL, Thongprasert S, Yang CH, Chu DT, et al. (2009) Gefitinib or carboplatin-paclitaxel in pulmonary adenocarcinoma. N Engl J Med 361: 947957.

5. Kwak EL, Bang YJ, Camidge DR, Shaw AT, Solomon B, et al. (2010) Anaplastic lymphoma kinase inhibition in non-small-cell lung cancer. N Engl J Med 363: 1693-1703.

6. Youlden DR, Cramb SM, Baade PD (2008) The international epidemiology of lung cancer: geographical distribution and secular trends. J Thorac Oncol 3: 819-831.

7. Turner N, Grose R (2010) Fibroblast growth factor signalling: from development to cancer. Nature Rev Cancer 10: 116-129.

8. Pollock PM, Gartside MG, Dejeza LC, Powell MA, Mallon MA, et al. (2007) Frequent activating FGFR2 mutations in endometrial carcinomas parallel germline mutations associated with craniosynostosis and skeletal dysplasia syndromes. Oncogene 26: 7158-7162.

9. Kunii K, Davis L, Gorenstein J, Hatch H, Yashiro M, et al. (2008) FGFR2amplified gastric cancer cell lines require FGFR2 and Erbb3 signaling for growth and survival. Cancer Res 68: 2340-2348.
10. Jang JH, Shin KH, Park JG (2001) Mutations in fibroblast growth factor receptor 2 and fibroblast growth factor receptor 3 genes associated with human gastric and colorectal cancers. Cancer Res 61: 3541-3543.

11. Cappellen D, De Oliveira C, Ricol D, de Medina S, Bourdin J, et al. (1999) Frequent activating mutations of FGFR3 in human bladder and cervix carcinomas. Nat Genet 23: 18-20.

12. Chesi M, Nardini E, Lim RS, Smith KD, Kuehl WM, et al. (1998) The t(4;14) translocation in myeloma dysregulates both FGFR3 and a novel gene, MMSET, resulting in IgH/MMSET hybrid transcripts. Blood 92: 3025-3034.

13. Taylor JG 6th, Cheuk AT, Tsang PS, Chung JY, Song YK, et al. (2009) Identification of FGFR4-activating mutations in human rhabdomyosarcomas that promote metastasis in xenotransplanted models. J Clin Invest 119: 3394 3407.

14. Reis-Filho JS, Simpson PT, Turner NC, Lambros MB, Jones C, et al. (2006) FGFR1 emerges as a potential therapeutic target for lobular breast carcinomas. Clin Cancer Res 12: 6652-6662.

15. Jaakkola S, Salmikangas P, Nylund S, Partanen J, Armstrong E, et al. (1993) Amplification of fgfr 4 gene in human breast and gynecological cancers. Int J Cancer 54: 378-382.

16. Weiss J, Sos ML, Seidel D, Peifer M, Zander T, et al. (2010) Frequent and focal FGFR1 amplification associates with therapeutically tractable FGFR1 dependency in squamous cell lung cancer. Sci tranl Med 2: 62ra93.

17. Dutt A, Ramos AH, Hammerman PS, Mermel C, Cho J, et al. (2011) Inhibitorsensitive FGFR1 amplification in human non-small cell lung cancer. PLoS ONE 6: e20351.

18. Davies H, Hunter C, Smith R, Stephens P, Greenman C, et al. (2005) Somatic mutations of the protein kinase gene family in human lung cancer. Cancer Res 65: 7591-7595.

19. Kan Z, Jaiswal BS, Stinson J, Janakiraman V, Bhatt D, et al. (2010) Diverse somatic mutation patterns and pathway alterations in human cancers. Nature 466: 869-873.

20. Bass AJ, Watanabe H, Mermel CH, Yu S, Perner S, et al. (2009) SOX2 is an amplified lineage-survival oncogene in lung and esophageal squamous cell carcinomas. Nat Gen 41: 1238-1242.

21. Marek L, Ware KE, Fritzsche A, Hercule P, Helton WR, et al. (2009) Fibroblast growth factor (FGF) and FGF receptor-mediated autocrine signaling in nonsmall-cell lung cancer cells. Mol Pharmacol 75: 196-207.

22. Platero S, Mokliatchouk O, Jayson GC, Jonker DJ, Rosen LS, et al. (2008) Correlation of FGF2 tumor expression with tumor response, PFS, and changes in plasma pharmacodynamic (PD) markers following treatment with brivanib alaninate, an oral dual inhibitor of VEGFR and FGFR tyrosine kinases. J Clin Oncol 26: 3506

23. Jonker DJ, Rosen LS, Sawyer MB, de Braud F, Wilding G, et al. (2011) A phase I study to determine the safety, pharmacokinetics and pharmacodynamics of a dual VEGFR and FGFR inhibitor, brivanib, in patients with advanced or metastatic solid tumors. Ann Oncol 22: 1413-1419.

24. Kim KB, Chesney J, Robinson D, Gardner H, Shi MM, et al. (2011) Phase I/ II and pharmacodynamic study of dovitinib (TKI258), an inhibitor of fibroblas growth factor receptors and VEGF receptors, in patients with advanced melanoma. Clin Cancer Res 17: 7451-7461.

25. Sarker D, Molife R, Evans TR, Hardie M, Marriott C, et al. (2008) A phase pharmacokinetic and pharmacodynamic study of TKI258, an oral, multitargeted receptor tyrosine kinase inhibitor in patients with advanced solid tumors. Clin Cancer Res 14: 2075-2081.

26. Wang X, Kay A, Anak O, Angevin E, Escudier B, et al. (2012) Population Pharmacokinetic/Pharmacodynamic Modeling to Assist Dosing Schedule Selection for Dovitinib. J Clin Pharmacol [Epub ahead of print].

27. Guagnano V, Furet P, Spanka C, Bordas V, Le Douget M, et al. (2011) Discovery of 3-(2,6-dichloro-3,5-dimethoxy-phenyl)-1-\{6-[4-(4-ethyl-piperazin1-yl)-phenylamino]-pyrimidin-4-yl\}-1-methyl-urea (NVP-BGJ398), a potent and selective inhibitor of the fibroblast growth factor receptor family of receptor tyrosine kinase. J Med Chem 54: 7066-7083. 
28. Zhao G, Li WY, Chen D, Henry JR, Li HY, et al. (2011) A novel, selective inhibitor of fibroblast growth factor receptors that shows a potent broad spectrum of antitumor activity in several tumor xenograft models. Mol Cancer Ther 10: 2200-2210.

29. Huang WS, Metcalf CA, Sundaramoorthi R, Wang Y, Zou D, et al. (2010) Discovery of 3-[2-(imidazo[1,2-b]pyridazin-3-yl)ethynyl]-4-methyl-N-\{4-[(4methylpiperazin-1-yl)methyl]-3-(trifluoromethyl)phenyl\}benzamide (AP24534), a potent, orally active pan-inhibitor of breakpoint cluster region-abelson (BCR$A B L$ ) kinase including the T315l gatekeeper mutant. J Med Chem 53: 47014719.

30. Gozgit JM, Wong MJ, Moran L, Wardwell S, Mohemmad QK, et al. (2012) Ponatinib (AP24534), a Multitargeted Pan-FGFR Inhibitor with Activity in Multiple FGFR-Amplified or Mutated Cancer Models. Mol Cancer Ther 11: 690699.

31. Cortes JE, Kim DW, Pinilla J, le Coutre P, Chuah C et al. (2011) Initial findings from the PACE trial: A pivotal phase 2 study of ponatinib in patients with CML and $\mathrm{Ph}+\mathrm{ALL}$ resistant or intolerant to dasatinib or nilotinib, or with the $\mathrm{T} 315 \mathrm{I}$ mutation. Abstr 109. $53^{\text {rd }} \mathrm{ASH}$ annual meeting, San Diego, CA on December $11,2011$.

32. Engelman JA (2009) Targeting PI3K signalling in cancer: opportunities, challenges and limitations. Nat Rev Cancer 9: 550-562.

33. Li J, Yen C, Liaw D, Podsypanina K, Bose S, et al. (1997) PTEN, a putative protein tyrosine phosphatase gene mutated in human brain, breast, and prostate cancer. Science 275: 1943-1947.

34. Engelman JA, Chen L, Tan X, Crosby K, Guimaraes AR, et al. (2008) Effective use of PI3K and MEK inhibitors to treat mutant Kras G12D and PIK3CA H1047R murine lung cancers. Nat Med 14: 1351-1356.

35. Rekhtman N, Paik PK, Arcila ME, Tafe LJ, Oxnard GR, et al. (2012) Clarifying the Spectrum of Driver Oncogene Mutations in Biomarker-Verified Squamous Carcinoma of Lung: Lack of EGFR/KRAS and Presence of PIK3CA/AKT1 Mutations. Clin Cancer Res 18: 1167-1176.

36. Sequist LV, Heist RS, Shaw AT, Fidias P, Rosovsky R, et al. (2011) Implementing multiplexed genotyping of non-small-cell lung cancers into routine clinical practice. Ann Oncol 22: 2616-2624.

37. Okudela K, Suzuki M, Kageyama S, Bunai T, Nagura K, et al. (2007) PIK3CA mutation and amplification in human lung cancer. Pathol Int 57: 664-671.

38. Janku F, Tsimberidou AM, Garrido-Laguna I, Wang X, Luthra R, et al. (2011) PIK3CA mutations in patients with advanced cancers treated with PI3K/AKT/ mTOR axis inhibitors. Mol Cancer Ther 10: 558-565.

39. Massion PP, Kuo WL, Stokoe D, Olshen AB, Treseler PA, et al. (2002) Genomic copy number analysis of non-small cell lung cancer using array comparative genomic hybridization: implications of the phosphatidylinosito 3-kinase pathway. Cancer Res 62: 3636-3640.

40. Ihle NT, Lemos R Jr, Wipf P, Yacoub A, Mitchell C, et al. (2009) Mutations in the phosphatidylinositol-3-kinase pathway predict for antitumor activity of the inhibitor PX-866 whereas oncogenic Ras is a dominant predictor for resistance. Cancer Res 69: 143-150.

41. Chaft JE, Arcila ME, Paik PK, Lau C, Riely GJ, et al. (2012) Coexistence of PIK3CA and other oncogene mutations in lung adenocarcinoma-rationale for comprehensive mutation profiling. Mol Cancer Ther 11: 485-491.

42. Soria JC, Lee HY, Lee JI, Wang L, Issa JP, et al. (2002) Lack of PTEN expression in non-small cell lung cancer could be related to promoter methylation. Clin Cancer Res 8: 1178-1184.

43. Marsit CJ, Zheng S, Aldape K, Hinds PW, Nelson HH, et al. (2005) PTEN expression in non-small-cell lung cancer: evaluating its relation to tumo characteristics, allelic loss, and epigenetic alteration. Hum Pathol 36: 768-776.

44. Zolota VG, Tzelepi VN, Leotsinidis M, Zili PE, Panagopoulos ND, et al. (2010) Histologic-type specific role of cell cycle regulators in non-small cell lung carcinoma. J Surg Res 164: 256-265.

45. Wee S, Wiederschain D, Maira SM, Loo A, Miller C, et al. (2008) PTEN-deficient cancers depend on PIK3CB. Pros Natl Acad Sci U S A 105: 13057-13062.

46. Edgar KA, Wallin JJ, Berry M, Lee LB, Prior WW, et al. (2010) Isoform-specific phosphoinositide 3-kinase inhibitors exert distinct effects in solid tumors. Cancer Res 70: 1164-1172.
47. Gonzalez E, McGraw TE (2009) The Akt kinases: isoform specificity in metabolism and cancer. Cell Cycle 8: 2502-2508.

48. Carpten JD, Faber AL, Horn C, Donoho GP, Briggs SL, et al. (2007) A transforming mutation in the pleckstrin homology domain of AKT1 in cancer. Nature 448: 439-444.

49. Do H, Salemi R, Murone C, Mitchell PL, Dobrovic A (2010) Rarity of AKT1 and AKT3 E17K mutations in squamous cell carcinoma of lung. Cell Cycle 9 : $4411-4412$.

50. Malanga D, Scrima M, De Marco C, Fabiani F, De Rosa N, et al. (2008) Activating $\mathrm{E} 17 \mathrm{~K}$ mutation in the gene encoding the protein kinase AKT1 in a subset of squamous cell carcinoma of the lung. Cell Cycle 7: 665-669.

51. Bleeker FE, Felicioni L, Buttitta F, Lamba S, Cardone L, et al. (2008) AKT1(E17K) in human solid tumours. Oncogene 27: 5648-5650.

52. Liu Y, Shreder KR, Gai W, Corral S, Ferris DK, et al. (2005) Wortmannin, a widely used phosphoinositide 3-kinase inhibitor, also potently inhibits mammalian polo-like kinase. Chem Biol 12: 99-107.

53. Rommel C, Camps M, Ji H (2007) PI3K delta and PI3K gamma: partners in crime in inflammation in rheumatoid arthritis and beyond? Nat Rev Immuno 7: 191-201.

54. http://clinicaltrials.gov/ct2/show/NCT00695448?term=GSK1059615\&rank=1

55. Groen HJM, Adjei AA, Dy GK, Ware JA, Shankar G, et al. (2011) A phase Ib study to evaluate the PI3-kinase inhibitor GDC-0941 with paclitaxel $(P)$ and carboplatin (C), with or without bevacizumab (BEV), in patients with advanced non-small cell lung cancer (NSCLC). European Multidisciplinary Cancer Congress, Stockholm, Sweden September 26, 2011. Abstr 9012.

56. Maira SM, Pecchi S, Huang A, Burger M, Knapp M, et al. (2012) Identification and characterization of NVP-BKM120, an orally available pan-class I PI3kinase inhibitor. Mol Cancer Ther 11: 317-328.

57. Bendell JC, Rodon J, Burris HA, de Jonge M, Verweij J, et al. (2012) Phase I dose-escalation study of BKM120, an oral pan-Class I PI3K inhibitor, in patients with advanced solid tumors. J Clin Oncol 30: 282-290.

58. Edelman G, Bedell C, Shapiro G, Pandya SS, Kwak EL, et al. (2010) A phase I dose-escalation study of XL147 (SAR245408), a PI3K inhibitor administered orally to patients (pts) with advanced malignancies. J Clin Oncol 28: 15s (abstr 3004)

59. Yaguchi S, Fukui Y, Koshimizu I, Yoshimi H, Matsuno T, et al. (2006) Antitumor activity of ZSTK474, a new phosphatidylinositol 3-kinase inhibitor. J Nat Cancer Inst 98: 545-556.

60. Ihle NT, Williams R, Chow S, Chew W, Berggren MI, et al. (2004) Molecular pharmacology and antitumor activity of PX-866, a novel inhibitor of phosphoinositide-3-kinase signaling. Mol Cancer Ther 3: 763-772.

61. Jimeno A, Herbst RS, Falchook GS, Messersmith WA, Hecker S, et al. (2010) Final results from a phase I, dose-escalation study of PX-866, an irreversible, pan-isoform inhibitor of PI3 kinase. J Clin Oncol 28: 15s (abstr 3089).

62. Tanaka H, Yoshida M, Tanimura H, Fujii T, Sakata K, et al. (2011) The selective class I PI3K inhibitor $\mathrm{CH} 5132799$ targets human cancers harboring oncogenic PIK3CA mutations. Clin Cancer Res 17: 3272-3281.

63. Carracedo A, Pandolfi PP (2008) The PTEN-PI3K pathway: of feedbacks and cross-talks. Oncogene 27: 5527-5541.

64. Yuan J, Mehta PP, Yin MJ, Sun S, Zou A, et al. (2011) PF-04691502, a potent and selective oral inhibitor of PI3K and mTOR kinases with antitumor activity. Mol Cancer Ther 10: 2189-2199.

65. Mallon R, Feldberg LR, Lucas J, Chaudhary I, Dehnhardt C, et al. (2011) Antitumor efficacy of PKI-587, a highly potent dual PI3K/mTOR kinase inhibitor. Clin Cancer Res 17: 3193-3203.

66. Lo Russo PM, Britten C, Millham R, Borzillo G, Houk B, et al. (2011) First-inpatient study of PF-04691502, a small-molecule intravenous oral dual inhibito of PI3K and mTOR in patients with advanced cancer: update on safety, efficacy, and pharmacology. Mol Cancer Ther 10: Suppl 1, AbstrB163.

67. Millham R, Houk B, Borzillo G, Tabernero J, Bell-McGuinn K, et al. (2011) Firstin-patient study of PF-05212384, a small molecule intravenous dual inhibitor of $\mathrm{PI} 3 \mathrm{~K}$ and mTOR in patients with advanced cancer: update on safety, efficacy and pharmacology. Mol Cancer Ther 10: Suppl 1, Abstr A167. 
68. Serra V, Markman B, Scaltriti M, Eichhorn PJ, Valero V, et al. (2008) NVP $\mathrm{BEZ235}$, a dual PI3K/mTOR inhibitor, prevents PI3K signaling and inhibits the growth of cancer cells with activating PI3K mutations. Cancer Res 68: 80228030.

69. Burris H, Rodon J, Sharma S, Herbst RS, Tabernero J, et al. (2010) First-in human phase I study of the oral PI3K inhibitor BEZ235 in patients (pts) with advanced solid tumors. J Clin Oncol 28: 15s (abstr 3005).

70. Serra V, Scaltriti M, Prudkin L, Eichhorn PJ, Ibrahim YH, et al. (2011) PI3K inhibition results in enhanced HER signaling and acquired ERK dependency in HER2-overexpressing breast cancer. Oncogene 30: 2547-2557.

71. Okuzumi T, Fiedler D, Zhang C, Gray DC, Aizenstein B, et al. (2009) Inhibitor hijacking of Akt activation. Nat Chem Biol 5: 484-493.

72. Yap TA, Yan L, Patnaik A, Fearen I, Olmos D, et al. (2011) First-in-man clinica trial of the oral pan-AKT inhibitor MK-2206 in patients with advanced solid tumors. J Clin Oncol 29: 4688-4695.

73. Cherrin C, Haskell K, Howell B, Jones R, Leander K, et al. (2010) An allosteric Akt inhibitor effectively blocks Akt signaling and tumor growth with only transient effects on glucose and insulin levels in vivo. Cancer Biol Ther 9: 493-503.

74. Davies BR, Greenwood H, Dudley P, Crafter C, Yu DH, et al. (2012) Preclinical pharmacology of AZD5363, an orally bioavailable inhibitor of AKT: pharmacodynamics, antitumor activity and correlation of monotherapy activity with genetic background. Mol Cancer Ther [Epub ahead of print].

75. Liu R, Liu D, Trink E, Bojdani E, Ning G, et al. (2011) The Akt-specific inhibito MK2206 selectively inhibits thyroid cancer cells harboring mutations that can activate the PI3K/Akt pathway. J Clin Endocrinol Metab 96: E577-E585.

76. Meng J, Dai B, Fang B, Bekele BN, Bornmann WG, et al. (2010) Combination treatment with MEK and AKT inhibitors is more effective than each drug alone in human non-small cell lung cancer in vitro and in vivo. PloS One 5: e14124

77. Yang K, Kim JH, Kim HJ, Park IS, Kim IY, et al. (2005) Tyrosine 740 phosphorylation of discoidin domain receptor 2 by Src stimulates intramolecular autophosphorylation and Shc signaling complex formation. J Biol Chem 280 39058-39066.

78. Vogel W, Gish GD, Alves F, Pawson T (1997) The discoidin domain receptor tyrosine kinases are activated by collagen. Mol Cell 1: 13-23.

79. Hammerman PS, Sos ML, Ramos AH, Xu C, Dutt A, et al. (2011) Mutations in the DDR2 kinase gene identify a novel therapeutic target in squamous cell lung cancer. Cancer Discov 1: 78-89.

80. Day E, Waters B, Spiegel K, Alnadaf T, Manley PW, et al. (2008) Inhibition of collagen-induced discoidin domain receptor 1 and 2 activation by imatinib, nilotinib and dasatinib. Eur J Pharmacol 599: 44-53.

81. Kumar R, Crouthamel MC, Rominger DH, Gontarek RR, Tummino PJ, et al. (2009) Myelosuppression and kinase selectivity of multikinase angiogenesis inhibitors. Br J Cancer 101: 1717-1723.

82. Hilberg F, Roth GJ, Krssak M, Kautschitsch S, Sommergruber W, et al. (2008) BIBF 1120: triple angiokinase inhibitor with sustained receptor blockade and good antitumor efficacy. Cancer Res 68: 4774-4782.

83. Squires M, Ward G, Saxty G, Berdini V, Cleasby A, et al. (2011) Potent selective inhibitors of fibroblast growth factor receptor define fibroblast growth factor dependence in preclinical cancer models. Mol Cancer Ther 10: 15421552.

84. Wedge SR, Kendrew J, Hennequin LF, Valentine PJ, Barry ST, et al. (2005) AZD2171: a highly potent, orally bioavailable, vascular endothelial growth factor receptor-2 tyrosine kinase inhibitor for the treatment of cancer. Cancer Res 65: 4389-4400.

85. Kania RS (2009) Structure-based design and characterization of axitinib. Page 194 in Kinase inhibitor drugs. Edited by Li R, Stafford JA. John Wiley and Sons, Hoboken NJ.

86. Gavine P, Mooney L, Kilgour E, et al. (2011) Characterization of AZD4547: An

This article was originally published in a special issue, Lung Cancer handled by Editor(s). Dr. Harvey I. Pass, NYU Langone Medical Center, Canada orally bioavailable, potent and selective inhibitor of FGFR tyrosine kinases 1, 2 and 3. 102nd AACR Annual Meeting, 2011 Apr 2-6; Orlando, FL.

87. Wilhelm SM, Dumas J, Adnane L, Lynch M, Carter CA, et al. (2011) Regorafenib (BAY 73-4506): a new oral multikinase inhibitor of angiogenic, stromal and oncogenic receptor tyrosine kinases with potent preclinical antitumor activity. Int J Cancer 129: 245-255.

88. Smith DC, Britten C, Clary DO, Nguyen LT, Woodard P, et al. (2009) A phase study of XL228, a potent IGF1R/AURORA/SRC inhibitor, in patients with solid tumors or hematologic malignancies. J Clin Oncol 27: 15s (abstr 3512).

89. Folkes AJ, Ahmadi K, Alderton WK, Alix S, Baker SJ, et al. (2008) The identification of 2-(1H-indazol-4-yl)-6-(4-methanesulfonyl-piperazin-1-ylmethyl)4-morpholin-4-yl-thieno[3,2-d]pyrimidine (GDC-0941) as a potent, selective orally bioavailable inhibitor of class I PI3 kinase for the treatment of cancer. $J$ Med Chem 51: 5522-5532

90. Raynaud FI, Eccles SA, Patel S, Alix S, Box G, et al. (2009) Biological properties of potent inhibitors of class I phosphatidylinositide 3-kinases: from $\mathrm{PI}-103$ through PI-540, PI-620 to the oral agent GDC-0941. Mol Cancer Ther 8: $1725-1738$.

91. Kong D, Yamori T (2008) Phosphatidylinositol 3-kinase inhibitors: promising drug candidates for cancer therapy. Cancer Sci 99: 1734-1740.

92. Shuttleworth SJ, Silva FA, Cecil AR, Tomassi CD, Hill TJ, et al. (2011) Progress in the preclinical discovery and clinical development of class I and dual class I/ IV phosphoinositide 3-kinase (PI3K) inhibitors. Curr Med Chem 18: 2686-2714

93. Kong D, Yamori T (2007) ZSTK474 is an ATP-competitive inhibitor of class phosphatidylinositol 3 kinase isoforms. Cancer Sci 98: 1638-1642.

94. Herman SE, Gordon AL, Wagner AJ, Heerema NA, Zhao W, et al. (2010) Phosphatidylinositol 3-kinase- $\delta$ inhibitor CAL-101 shows promising preclinical activity in chronic lymphocytic leukemia by antagonizing intrinsic and extrinsic cellular survival signals. Blood 116: 2078-2088.

95. Knight SD, Adams ND, Burgess JL, Chaudhari AM, Darcy MG, et al. (2010) Discovery of GSK2126458, a highly potent inhibitor of PI3K and the mammalian target of rapamycin. ACS Med Chem Lett 1: 39-43.

96. Molckovsky A, Siu LL (2008) First-in-class, first-in-human phase I results of targeted agents: highlights of the 2008 American society of clinical oncology meeting. J Hematol Oncol 1: 20.

97. Maira SM, Stauffer F, Brueggen J, Furet P, Schnell C, et al. (2008) Identification and characterization of NVP-BEZ235, a new orally available dual phosphatidylinositol 3-kinase/mammalian target of rapamycin inhibitor with potent in vivo antitumor activity. Mol Cancer Ther 7: 1851-1863.

98. Garlich JR, De P, Dey N, Su JD, Peng X, et al. (2008) A vascular targeted pan phosphoinositide 3-kinase inhibitor prodrug, SF1126, with antitumor and antiangiogenic activity. Cancer Res 68: 206-215.

99. Sutherlin DP, Bao L, Berry M, Castanedo G, Chuckowree I, et al. (2011) Discovery of a potent, selective, and orally available class I phosphatidylinosito 3-kinase (PI3K)/mammalian target of rapamycin (mTOR) kinase inhibitor (GDC-0980) for the treatment of cancer. J Med Chem 54: 7579-7587 